\title{
Rosmarinic and Cinnamic Acid Derivatives of in vitro Tissue Culture of Plectranthus ornatus: Overproduction and Correlation with Antioxidant Activities
}

\author{
Héctor H. Medrado, ${ }^{a}$ Edlene O. dos Santos, ${ }^{a}$ Erika M. O. Ribeiro, ${ }^{a}$ Jorge M. David, ${ }^{a}$ \\ Juceni P. David, ${ }^{*, a, b}$ José Fernando Araújo, ${ }^{b}$ Ademir E. do Vale, ${ }^{b}$ Moema C. Bellintani, ${ }^{c}$ \\ Hugo N. Brandão ${ }^{d}$ and Paloma R. Meira ${ }^{d}$ \\ ${ }^{a}$ Instituto de Química, ${ }^{b}$ Faculdade de Farmácia and ${ }^{c}$ Instituto de Biologia, Universidade Federal da \\ Bahia, Campus de Ondina, 40170-290 Salvador-BA, Brazil \\ ${ }^{d}$ Universidade Estadual de Feira de Santana, Av. Transnordestina, S/N, Bairro Novo Horizonte, \\ 44036-900 Feira de Santana-BA, Brazil
}

\begin{abstract}
This work describes the tissue culture of Plectranthus ornatus Codd. (Lamiaceae) on Murashige and Skoog (MS) medium with naphthalene acetic acid (NAA) (1.0, 2.0 and $4.0 \mathrm{mg} \mathrm{L}^{-1}$ ) and 6-benzylaminopurine (BAP) (1.0, 2.0 and $\left.4.0 \mathrm{mg} \mathrm{L}^{-1}\right)$ as growth regulators to obtain the overproduction of rosmarinic acid. The content of rosmarinic acid and its biosynthetic precursors were determined by high performance liquid chromatography (HPLC). The antioxidant activities (AA) of the extracts were also evaluated by 2,2-diphenyl-1-picrylhydrazyl (DPPH) assay. The best growing condition was observed with the addition of $1.0 \mathrm{mg} \mathrm{L}^{-1}$ of both NAA and BAP in the culture medium yielded an increase of 94 times of rosmarinic acid comparing with the wild plant. All extracts diplayed antioxidant activity, as evidenced by the DPPH free radical scavenging assay. However, those with $2.0 \mathrm{mg} \mathrm{L}^{-1}$ $\mathrm{NAA}$ and, $1.0 \mathrm{mg} \mathrm{L}^{-1} \mathrm{NAA}$ and BAP in culture medium showed the lowest $\mathrm{EC}_{50}(26.0$ and $29.8 \mu \mathrm{g}$ $\mathrm{mL}^{-1}$, respectively). At concentration higher than $10 \mu \mathrm{g} \mathrm{mL}-1$ of rosmarinic acid it was not observed the correlation with AA, suggesting some other anti-oxidant mechanism acting.
\end{abstract}

Keywords: rosmarinic acid, Plectranthus ornatus, in vitro tissue culture, caffeic acid

\section{Introduction}

Lamiaceae family embraces many important commercial species, such as sage (Salvia officinalis), basil (Ocimum basilicum L.) and mint (Mentha sp.). ${ }^{1}$ Plectranthus is an important genus of this family once their species have been used in folk medicine against a range of disorders. Plectranthus ornatus Codd is an aromatic herb known in Brazil as "boldo", "boldo-de-jardim", or "boldo-do-Brasil". This species is used in folk medicine to treat liver failure and dyspepsia. Studies on the chemical composition of the essential oils of the Plectranthus genus show that species of this genus are rich in monoterpenes and sesquiterpenes. ${ }^{2}$

Their species also contain compounds showing significant biological activity, ${ }^{3}$ among them rosmarinic acid (Figure 1) which has attracted the attention due to its broad spectrum of biological activities which include neuroprotective, anti-inflammatory, antimutagenic,

*e-mail: juceni@ufba.br antibacterial and antiviral. ${ }^{4}$ The cinnamic acid derivatives are also compounds commonly found in Lamiaceae species and, antioxidant activity is the most characteristic one of these compounds. ${ }^{5}$<smiles>O=C(/C=C/c1ccc(O)c(O)c1)OC(Cc1ccc(O)c(O)c1)C(=O)O</smiles><smiles>O=C(O)/C=C/c1ccc(O)c(O)c1</smiles><smiles>[R]c1ccc(/C=C/C(=O)O)c([R3])c1[R2]</smiles>

$$
\begin{aligned}
& 3 \mathrm{R}_{1}=\mathrm{OH}, \mathrm{R}_{2}=\mathrm{H}, \mathrm{R}_{3}=\mathrm{H} \\
& 4 \mathrm{R}_{1}=\mathrm{H}, \mathrm{R}_{2}=\mathrm{OH}, \mathrm{R}_{3}=\mathrm{H} \\
& \text { 5 } \mathrm{R}_{1}=\mathrm{H}, \mathrm{R}_{2}=\mathrm{H}, \mathrm{R}_{3}=\mathrm{OH}
\end{aligned}
$$

Figure 1. Rosmarinic (1), caffeic (2), $p$-, $m$ - and $o$-hydroxycinnamic (3-5) acids from Plecthrantus ornatus.

These bioactive compounds are mostly produced by intact plants in very small yield. Therefore, combining biotechnology techniques for the production of secondary metabolites, especially active compounds by cell culture, provides a new reliable source of natural compounds of 
pharmaceutical or commercial interests. So, plant cell culture prospections provide an alternative approach which may be interesting when the cultivation of an specific plant is difficult, it produces significant bioactive compounds and, in some cases, mass cultivation of the source plant may not be possible due to environmental, ecological or climatic conditions. Depending on the type of the vegetal material, extraction of secondary metabolites directly from cultivated plant tissue may be an option. In this context, the callus cultures are the first stage in plant biomass cultivation processes. ${ }^{6}$ This work describes a method of in vitro tissue culture of Plectranthus ornatus for overproduction of rosmarinic acid (1) and its relation to synthesis of caffeic and $o-, m$ - and $p$-hydroxycinnamic acids (2-5) enabling P. ornatus to become one source of rosmarinic acid.

\section{Experimental}

\section{Plant material}

Wild P. ornatus were collected nearby of the Instituto de Química of Universidade Federal da Bahia (UFBA) and identified by Prof Maria L. S. Guedes and a voucher has been previously deposited at the Herbarium of Museu Nacional of Universidade Federal do Rio de Janeiro under number R196538.

\section{Preparation of extracts}

The extracts were prepared from in natura specimens after the leaves, stems and inflorescences separation. The extracts obtained from the callus were obtained from the entire plant material with no distinction between organs and seedling of $P$. ornatus. Then, each of these materials were washed and dried in oven with aeration at $40{ }^{\circ} \mathrm{C}$, and subsequently ground. The ground plant material $(5.0 \mathrm{~g})$ was immersed in hot water $\left(80^{\circ} \mathrm{C}\right)$ infusion under stirring for 30 minutes and then filtered. The infusion process was repeated once more with the remaining solid residue from filtration. The two filtrates were combined and added $\mathrm{HCl} 25 \%$ (v/v) until the mixture reached $\mathrm{pH} 2-3$ in order to maintain the compounds of interest in acidic form. Thereafter, the mixture was partitioned three times between ethyl ether and $\mathrm{H}_{2} \mathrm{O}$. The ether portions were dried and submitted to high performance liquid chromatography with diode array detector (HPLC-DAD) analysis.

\section{In vitro culture production and establishment of $P$. ornatus}

All the explants were obtained from nodal segments, internodes with or without axillary buds, and leaves from mother (matrices) plants and they were disinfested by washing them in running water for 40 minutes in order to remove possible parasites or insects. Then, in a laminar flow chamber, the parts were immersed in ethanol $70 \%(\mathrm{v} / \mathrm{v})$ for 1 minute followed by sodium hypochlorite (2.0\% of active chlorine) and 3 drops of neutral detergent for 15 minutes. The segments were washed three times in sterile distilled water during 3 min each, after the first rinsed water $1 \mathrm{~mL}$ of alcoholic solution of acetic acid was added in order to neutralize the action of the hypochlorite solution.

The explants were inoculated into test tubes containing culture medium solidified with agar, sucrose and they were supplemented with auxins (Table 1) NAA (naphthalene acetic acid) and cytokinin BAP (6-benzylaminopurine). The $\mathrm{pH}$ was adjusted to 5.7 before autoclaving and, the test tubes containing the medium and the explants were kept in a dark room for eight days. Sequentially, during 30 days they were submitted to the photoperiod of 16 hours/day employing cold white light (Figure 2).

Table 1. Concentration in $\mathrm{mg} \mathrm{L}^{-1}$ of NAA and BAP in different cultivation conditions

\begin{tabular}{lcc}
\hline Condition & {$[\mathrm{NAA}] /\left(\mathrm{mg} \mathrm{L}^{-1}\right)$} & {$[\mathrm{BAP}] /\left(\mathrm{mg} \mathrm{L}^{-1}\right)$} \\
\hline 0 & 0 & 0 \\
A1 & 1 & 0 \\
A2 & 2 & 0 \\
A3 & 4 & 0 \\
B2 & 0 & 2 \\
B3 & 0 & 4 \\
C1 & 1 & 1 \\
\hline
\end{tabular}

\section{Determination of rosmarinic and cinnamic acid derivatives}

The prepared extracts were analyzed in a HPLC equipment (Dionex mod. 3000 Ultimate) with DAD scan range from 200 to $400 \mathrm{~nm}$ employing a Shimadzu VP-ODS C-18 chromatography column (150 mm of length, internal diameter $2 \mathrm{~mm}$, and $5 \mu \mathrm{m}$ particle size). The best HPLC separation was reach with a gradient of $\mathrm{MeOH}$ (28 to $62 \%$ ) and $0.1 \%$ acetic acid aqueous solution as mobile phase, in 10 min running time, flow rate of $1.0 \mathrm{~mL} \mathrm{~min}^{-1}$, at room temperature and $5 \mu \mathrm{L}$ of injection volume. The nuclear magnetic resonance (NMR) spectra were recorded in a performed using a Bruker mod. Avance III (resonance frequencies $300 \mathrm{MHz}$ for ${ }^{1} \mathrm{H}$ and $75 \mathrm{MHz}$ for ${ }^{13} \mathrm{C}$ ).

\section{Method validation}

The analytical method was validated for each pattern according to the parameters of selectivity, linearity, 

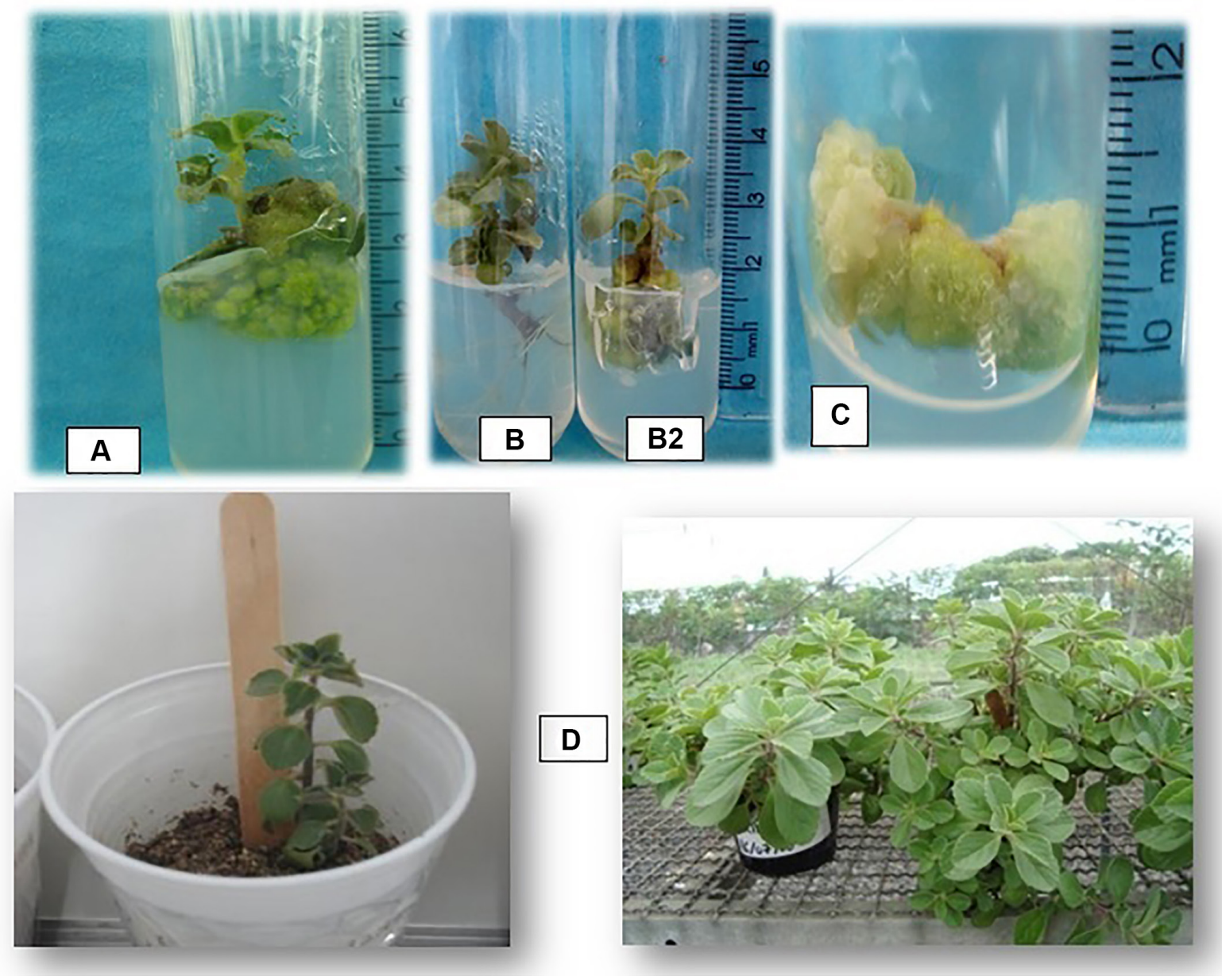

Figure 2. Morphological aspects of P. ornatus. (A) General appearance of shoots induced from nodal segments cultivated in medium supplemented with BAP and no NAA, after 30 days of cultivation; (B) general appearance of shoots induced from nodal segments cultivated in medium without supplemental regulators (B) and (B2) supplemented with BAP and NAA; (C) compact callus from nodal segments on MS medium supplemented with BAP and NAA; (D) transplanted plant in pot and acclimated plants.

precision, and accuracy, limit of detection (LOD) and limit of quantification (LOQ) according to literature (Table 2). ${ }^{7}$ Selectivity was determined by comparing the peaks of standards and samples, considering retention time, UV spectra and mass spectra of at least three different points of the chromatograms (beginning, half and end of peaks). Linearity was obtained by calibration curves using a correlation coefficient $\left(\mathrm{R}^{2}\right)$. Calibration curves were obtained by triplicate injections of different concentrations of three solutions of external standards. Standard solutions were prepared, covering the range from 5.0 to $100.0 \mathrm{~g} \mathrm{~mL}^{-1}$ for all standard compounds. Peak areas were correlated with the averages of each concentration, and a graph was plotted using the least squares method.

Precision was determined by injection in triplicate of three solutions of the standards. This parameter was expressed as the relative standard deviation according to the equation $\mathrm{RS}(\%)=\mathrm{SD} / \mathrm{AC} \times 100$, where $\mathrm{SD}$ is the standard deviation and $\mathrm{AC}$ is the average concentration determined. The accuracy was verified by recovery factor, where samples with no analytes were spiked with standard solutions of low, medium and high concentrations. The spiked samples were subjected to the whole process of extraction and were injected into HPLC.

The accuracy was determined by the following equation: $\operatorname{Rec}(\%)=$ [obtained concentration] $/$ [real concentration] $\times 100$.

The LOD and LOQ were estimated by the ratio of standard deviations and slopes of calibration curves, according to the equations $\mathrm{LOD}=\mathrm{SDa} \times 3 / \mathrm{S}$ and $\mathrm{LOQ}=\mathrm{SDa} \times 10 / \mathrm{S}$, where $\mathrm{SDa}$ is the standard deviation obtained from the calibration curve and $\mathrm{S}$ is the curve's slope.

\section{Determination of antioxidant activity by DPPH test}

The radical scavenging activity of the extracts were based on protocol previously described. ${ }^{8}$ The antioxidant 
Table 2. Overview of the validation parameters of the cinnamic acid derivatives and rosmarinic acid

\begin{tabular}{|c|c|c|c|c|c|}
\hline Parameter & $\begin{array}{c}\text { Caffeic } \\
\text { acid }\end{array}$ & $\begin{array}{l}o \text {-Hydroxycinnamic } \\
\text { acid }\end{array}$ & $\begin{array}{l}m \text {-Hydroxycinnamic } \\
\text { acid }\end{array}$ & $\begin{array}{l}p \text {-Hydroxycinnamic } \\
\text { acid }\end{array}$ & $\begin{array}{l}\text { Rosmarinic } \\
\text { acid }\end{array}$ \\
\hline Equation & $\mathrm{y}=0.8099 \mathrm{x}+0.0788$ & $y=1.1656 x+0.1588$ & $y=1.0108 x-0.1643$ & $y=0.3569 x+0.0446$ & $0.3569 x+0.0446$ \\
\hline Correlation coefficient & 0.99983 & 0.9998 & 0.99928 & 0.99981 & 0.99981 \\
\hline Concentration range / $\left(\mu \mathrm{g} \mathrm{mL}^{-1}\right)$ & $5-100$ & $5-100$ & $5-100$ & $5-100$ & $5-100$ \\
\hline $\mathrm{LOD} /\left(\mu \mathrm{g} \mathrm{mL} L^{-1}\right)$ & 1.3 & 1.6 & 0.4 & 2.2 & 2.1 \\
\hline $\mathrm{LOQ} /\left(\mu \mathrm{g} \mathrm{mL}^{-1}\right)$ & 4.2 & 5.3 & 1.5 & 7.2 & 6.9 \\
\hline $\mathrm{RSD} / \%$ & 3.7 & 4.3 & 3.8 & 3.2 & 2.0 \\
\hline Recovery / \% & 91 & 96 & 99 & 99 & 97 \\
\hline
\end{tabular}

LOD: limit of detection; LOQ: limit of quantification; RSD: relative standard deviation.

activity was measured at $517 \mathrm{~nm}$ using a PerkinElmer UV-Vis Spectrophotometer mod. Lambda 25 and the activity was expressed as $\mathrm{EC}_{50}$. Briefly, $200 \mu \mathrm{L}$ of ethanol extract was added in $3 \mathrm{~mL}$ of $60 \mu \mathrm{mol} \mathrm{L} \mathrm{L}^{-1}$ by 2,2-diphenyl-1picrylhydrazyl (DPPH) methanol solution freshly prepared. Standards of pure rosmarinic and caffeic acids (Sigma, 97\%) were employed as positive controls and in the control was the blank.

\section{Results and Discussion}

All the leaves, stem and root extracts of $P$. ornatus were submitted to HPLC-DAD analyses in order to identify the presence of rosmarinic (RA), caffeic (CA), $o$-hydroxycinnamic (o-OH-CIN), $p$-hydroxycinnamic ( $p$-OH-CIN) and $m$-hydroxycinnamic ( $m$-OH-CIN) acids through comparison with pure standards. The choice of these compounds was based on the chemical composition of Plecthrantus genus. Except for the $m$-hydroxycinnamic acid, all compounds were detected in the extracts obtained from the in natura and in vitro plant materials. All samples obtained from different conditions (A1, A2, A3, B2, B3 and $\mathrm{C} 1$ ) of in vitro cultivation are also analyzed. The chromatograms showed (Figure 3 ) retention time $\left(t_{\mathrm{R}}\right)$ of significant peaks of rosmarinic $\left(t_{\mathrm{R}}=6.3 \mathrm{~min}\right)$ and caffeic $\left(t_{\mathrm{R}}=2.1 \mathrm{~min}\right)$ acids. Table 3 summarizes the quantification of all samples prepared.

Despite some samples showed an additional peak at $t_{\mathrm{R}}=4.2 \mathrm{~min}$, with the same $t_{\mathrm{R}}$ peak of $m$-hydroxycinnamic acid, the UV spectra pattern recorded for this peak showed they were different compounds. Thus it was possible to confirm that no sample contained $m$-hydroxycinnamic acid.

The results indicated that rosmarinic and caffeic acids were found in higher concentrations in all samples analyzed (Table 3). The $p$-hydroxycinnamic acid was quantified in much lower concentration compared to others. The $o$-hydroxy-cinnamic acid was just detected with concentrations above LOQ. The matrix plants indicate much lower levels of rosmarinic acid and caffeic acid when compared to all other growing conditions, including the control sample cultured in vitro without growth regulators addition (condition 0 ). Thus, the in vitro cultivated samples of Plectranthus ornatus showed increased production of these two compounds (increment of 4.5 to 50 times) as shown by the overlap of chromatograms of extracts of both samples, in scale and under the same conditions (Figure 3).

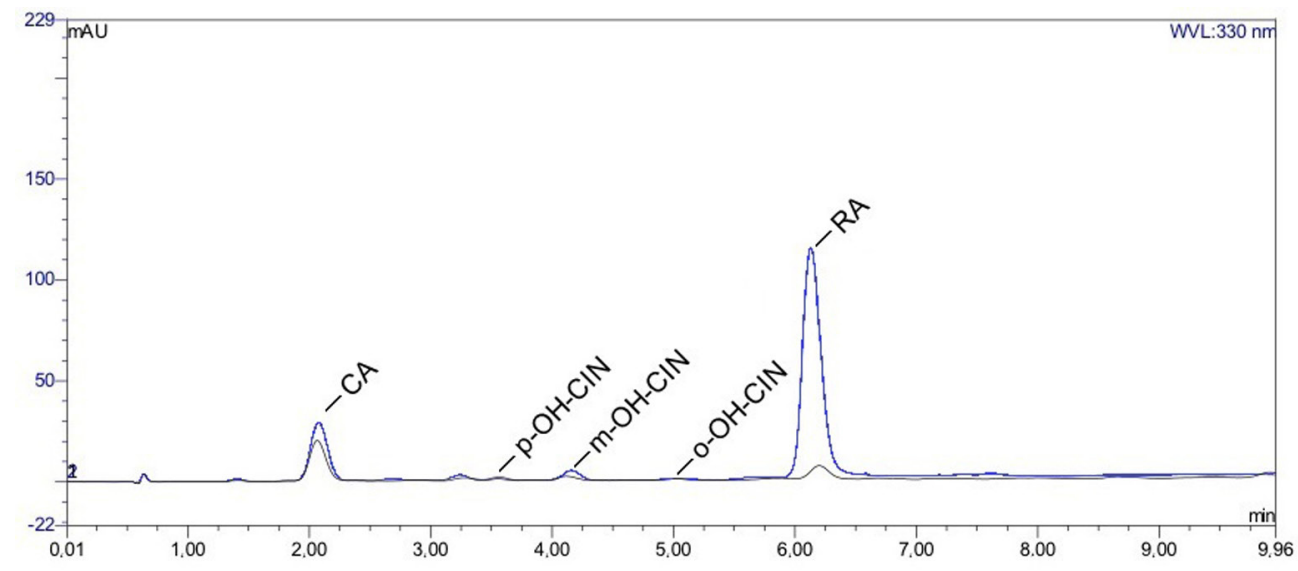

Figure 3. HPLC chromatogram extracts $\left(1 \mathrm{mg} \mathrm{mL}^{-1}\right)$ of matrix plant (black) and in vitro cultivated (blue) P. ornatus (control). 
Table 3. Analyte levels $\left(\mathrm{mg} \mathrm{kg}^{-1}\right)^{\mathrm{a}}$ in nature and in vitro Plecthrantus ornatus samples

\begin{tabular}{|c|c|c|c|c|}
\hline Condition & $\mathrm{CA} /\left(\mathrm{mg} \mathrm{kg}^{-1}\right)$ & $p$-OH-CIN / $\left(\mathrm{mg} \mathrm{kg}^{-1}\right)$ & $o-\mathrm{OH}-\mathrm{CIN} /\left(\mathrm{mg} \mathrm{kg}^{-1}\right)$ & $\mathrm{RA} /\left(\mathrm{mg} \mathrm{kg}^{-1}\right)$ \\
\hline Matrix & $84.8 \pm 2.1$ & $11.5 \pm 1.1$ & $<\mathrm{LOQ}$ & $64.3 \pm 0.3$ \\
\hline 0 & $378.2 \pm 8.8$ & $15.9 \pm 1.3$ & $<$ LOQ & $3,197.0 \pm 131.0$ \\
\hline A1 & $157.7 \pm 2.8$ & $16.5 \pm 0.8$ & $<$ LOQ & $4,028.0 \pm 113.0$ \\
\hline A2 & $284.3 \pm 7.7$ & $16.0 \pm 1.6$ & $<$ LOQ & $3,971.0 \pm 94.0$ \\
\hline A3 & $400.8 \pm 7.8$ & $14.9 \pm 1.9$ & $<$ LOQ & $5,125.0 \pm 60.0$ \\
\hline B2 & $111.5 \pm 1.8$ & $5.0 \pm 0.7$ & $<$ LOQ & $3,006.0 \pm 62.0$ \\
\hline B3 & $158.3 \pm 6.1$ & $17.1 \pm 1.5$ & $<$ LOQ & $1,763.0 \pm 63.0$ \\
\hline $\mathrm{C} 1$ & $116.2 \pm 3.3$ & $6.6 \pm 0.4$ & $<$ LOQ & $6,206.0 \pm 166.0$ \\
\hline
\end{tabular}

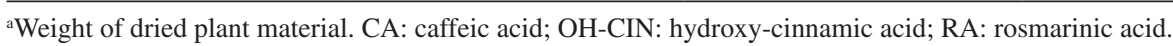

The established plants which NAA was employed as growth regulator show that the increasing production of caffeic acid is directly related with the increment concentration of this regulator. Moreover, the synthesis of rosmarinic acid under $\mathrm{A} 1$ ( $\left.1 \mathrm{mg} \mathrm{L}^{-1} \mathrm{NAA}\right)$ and A2 $\left(2 \mathrm{mg} \mathrm{L}^{-1} \mathrm{NAA}\right)$ growth conditions showed no significant change in their concentrations, since the confidence intervals are overlapping. In the samples under B2 and B3 conditions, it was found that the concentration of BAP in the 2 to $4 \mathrm{mg} \mathrm{L}^{-1}$ intervals favored increment of $40 \%$ in the caffeic acid production and reduced $60 \%$ the biosynthesis of rosmarinic acid.

The best culture condition was obtained with $1 \mathrm{mg} \mathrm{L}^{-1}$ NAA and $1 \mathrm{mg} \mathrm{L}^{-1} \mathrm{BAP}$ addition, which besides producing callus, decreased the production of caffeic acid and provided the highest yield of rosmarinic acid. This condition among all analyzed samples, exceeding in 96 times the matrix for the production of rosmarinic acid, accumulating $6.2 \mathrm{~g}$ of this metabolite for each kilogram of dry plant material. To confirm these findings, ${ }^{1} \mathrm{H}$ and ${ }^{13} \mathrm{C}$ NMR spectra of this extract were recorded. Data analyses of them and comparison with literature data ${ }^{9}$ permitted to attest it consists in the majority by rosmarinic acid and also with caffeic acid.

Compared to previous works aiming the production of rosmarinic acid through in vitro cultivation of plants, ${ }^{10}$ this study showed the highest percentage of rosmarinic acid production in relation to the wild mother plant.

The evaluation of the quenching of radical DDPH $\left(\mathrm{EC}_{50}\right)$ of the matrix extract, controls (condition 0 ) and extracts of the different cultivation conditions employing NAA (A1, $\mathrm{A} 2$ and $\mathrm{A} 3)$ and, BAP (B2 and B3) and $\mathrm{C} 1$ (BAP + NAA) are described in the Table 4 . All evaluated extracts showed antioxidant activity, and the extracts obtained from in vitro establishment of $P$. ornatus exceeded the antioxidant capacity of the wild plant. The extraction method showed to be adequate to rosmarinic acid and cinnamic acids, since some extracts concentrated more than $30 \%$ of the former compound, combined with high recovery rates shown in accuracy assay method.

Table 4. $\mathrm{DPPH} \mathrm{EC}_{50}$ of matrix and cultivated P. ornatus extracts, rosmarinic and caffeic acids (results calculated with $95 \%$ confidence)

\begin{tabular}{lc}
\hline Cultive condition & $\mathrm{EC}_{50} /\left(\mu \mathrm{g} \mathrm{mL}^{-1}\right)$ \\
\hline Matrix & $330.5 \pm 7.2$ \\
0 & $126.5 \pm 3.0$ \\
A1 & $39.7 \pm 2.4$ \\
A2 & $26.0 \pm 1.1$ \\
A3 & $35.1 \pm 1.4$ \\
B2 & $40.3 \pm 2.1$ \\
B3 & $60.3 \pm 2.8$ \\
C1 & $29.8 \pm 1.5$ \\
RA & $9.7 \pm 0.8$ \\
CA & $6.3 \pm 0.7$ \\
\hline
\end{tabular}

In the presence of growth regulators, samples exclusively cultured with NAA (conditions A1, A2 and A3) showed higher antioxidant activity in comparison with the matrix or control. Among the samples grown with BAP, the B2 condition showed higher antioxidant activity. Though the extracts of cultivation conditions B2 and B3 had lower antioxidant activities than those of NAA conditions, they exhibited higher AA than those of matrix and control (condition 0). The results are in accordance with the concentrations of rosmarinic and caffeic acid in these extracts (Table 5). The concentration of rosmarinic acid in the matrix plant extract was lower than caffeic acid, but higher in all in vitro cultivations.

The Figure 4A shows rosmarinic acid contents present in the extracts and $\mathrm{EC}_{50}$ have a strong correlation of the logarithmic type $\left(\mathrm{R}^{2}>0.95\right)$. However, it was possible to observe that extracts with concentrations of rosmarinic 

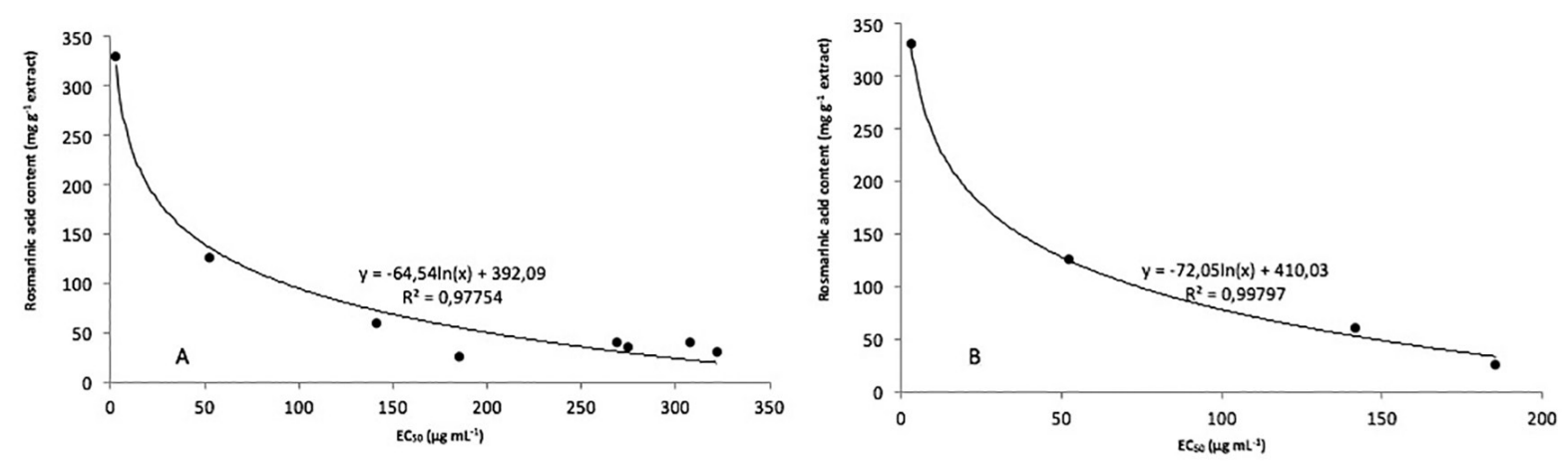

Figure 4. Rosmarinic acid contents and the DPPH (A), rosmarinic acid content $\left(<190 \mathrm{mg} \mathrm{g}^{-1}, \mathrm{~B}\right)$ and antioxidant activities of extracts.

Table 5. Rosmarinic (RA) and caffeic (CA) acids contents in the extracts $\left(\mathrm{mg} \mathrm{g}^{-1}\right.$ of extract)

\begin{tabular}{lcc}
\hline Sample & $\mathrm{RA} /\left(\mathrm{mg} \mathrm{g}^{-1}\right.$ of extract $)$ & $\mathrm{CA} /\left(\mathrm{mg} \mathrm{g}^{-1}\right.$ of extract $)$ \\
\hline Matrix & $3.0 \pm 0.2$ & $4.1 \pm 0.1$ \\
0 & $52.4 \pm 2.1$ & $6.2 \pm 0.1$ \\
A1 & $308.0 \pm 8.6$ & $12.1 \pm 0.2$ \\
A2 & $185.4 \pm 4.4$ & $13.3 \pm 0.4$ \\
A3 & $274.5 \pm 3.2$ & $21.5 \pm 0.4$ \\
B2 & $268.8 \pm 5.6$ & $10.0 \pm 0.2$ \\
B3 & $141.4 \pm 5.1$ & $12.7 \pm 0.5$ \\
C1 & $321.9 \pm 8.6$ & $6.0 \pm 0.2$ \\
\hline
\end{tabular}

acid above $190 \mathrm{mg} \mathrm{g}^{-1}$ the $\mathrm{EC}_{50}$ values do not respond proportionally to the increasing concentration (Figure 4B). However, excluding the point of extracts with rosmarinic acid concentrations above $190 \mathrm{mg} \mathrm{g}^{-1}(\mathrm{~A} 1, \mathrm{~A} 3, \mathrm{~B} 2, \mathrm{C} 1)$ the correlation is much stronger $\left(\mathrm{R}^{2}>0.99\right)$.

The lack of linear and logarithmic proportion or any other function can be attributed to the increment of concentration of caffeic acid and other phenolic compounds or, in a specific concentration this compound present prooxidative action instead of quenching the radical.

The $\mathrm{EC}_{50}$ values for free radical DPPH scavenging of rosmarinic and caffeic acid are 9.7 and $6.8 \mu \mathrm{g} \mathrm{mL} \mathrm{m}^{-1}$, respectively. None of the extracts reached $\mathrm{EC}_{50}$ similar than RA and CA values, which is consistent with the composition of these compounds in extracts.

\section{Conclusions}

The in vitro P. ornatus cultivation method for the overproduction of rosmarinic acid was effective with a considerable increasing in rosmarinic acid production comparing with the matrix plant. The best culture condition was obtained with NAA and BAP regulators addition, both at a concentration of $1 \mu \mathrm{g} \mathrm{mL} \mathrm{m}^{-1}$ with a content equal to $6.2 \mathrm{~g}$ of rosmarinic acid per kilogram of dry plant material.
So, this method is a contribution to the production of this bioactive natural compound. Free radical DPPH scavenging assays showed that all extracts of Plectranthus ornatus were rich in antioxidant compounds. The $\mathrm{EC}_{50}$ values were correlated with the levels of rosmarinic acid up to the concentration of $190 \mathrm{mg} \mathrm{g}^{-1}$ of extract. In higher concentrations of extracts a random variation of $\mathrm{EC}_{50}$ was observed with increasing concentration of rosmarinic acid. This fact could be attributed to other effects rather than the presence of rosmarinic acid, caffeic acid and other phenolic compounds in the extracts.

\section{Supplementary Information}

Supplementary information $\left({ }^{1} \mathrm{H}\right.$ and ${ }^{13} \mathrm{C}$ NMR spectra of $\mathrm{MeOH}$ extracts of shoots induced from nodal segments cultivated supplemented with BAP and NAA ) is available free of charge at http://jbcs.sbq.org.br as PDF file.

\section{Acknowledgments}

The authors thank CNPq (Conselho Nacional do Desenvolvimento Científico e Tecnológico), CAPES (Coordenação de Aperfeiçoaento de Pessoal de Nível Superior) and FAPESB (Fundação de Apoio à Pesquisa do Estado da Bahia) for the grants and scholarships.

\section{References}

1. Zgorka, G.; Glowniak, K.; J. Pharm. Biomed. Anal. 2001, 26, 79.

2. Passinho-Soares, H. C.; Meira, P. R.; David, J. P.; Mesquita, P. R. R.; do Vale, A. E.; Rodrigues, F. M. R.; Pereira, P. A. P.; de Santana, J. R. F.; de Oliveira, F. S.; de Andrade, J. B.; David, J. M.; Molecules 2013, 18, 10320.

3. Lukhoba, C. W.; Simmonds, M. S. J.; Paton, A. J.; J. Ethnopharmacol. 2006, 103, 1.

4. Petersen, M.; Simmonds, M. S. J.; Phytochemistry 2003, 62, 121. 
5. Liu, G.; Ruedi, P.; Phytochemistry 1996, 41, 1563.

6. Yesil-Celiktas, O.; Gurel, A.; Vardar-Sukan, F.; Large Scale Cultivation of Plant Cell and Tissue Culture in Bioreactors, $1^{\text {st }}$ ed.; Transworld Research Network: Kerala, India, 2010.

7. http://www.ich.org/products/guidelines/quality/qualitysingle/article/validation-of-analytical-procedures-text-andmethodology.html, accessed in November 2016.

8. Alves, C. Q.; David, J. M.; David, J. P.; Bahia, M. V.; Aguiar, R. M.; Quim. Nova 2010, 33, 2202; http://www.cnpat.embrapa.br/ download_publicacao.php?id=210, accessed in August 2016.
9. http://www.bmrb.wisc.edu, accessed in November 2016.

10. Mohagheghzadeh, A.; Shams-Ardakani, M.; Ghannadi, A.; Minaeian, M.; Fitoterapia 2004, 75, 315; Fattahia, M.; Nazerib, V.; Torras-Claveriac, L.; Sefidkond, F.; Cusidoc, R. M.; Zamanib, Z.; Palazonc, J.; Ind. Crops Prod. 2013, 50, 256.

Submitted: September 5, 2016 Published online: November 17, 2016 